\title{
EARLY TEMPERATURES OBSERVED WITH THE EXTREMELY SENSITIVE RAYLEIGH LIDAR AT UTAH STATE UNIVERSITY
}

\author{
Vincent B. Wickwar ${ }^{1 *}$, Leda Sox ${ }^{1}$, Matthew T. Emerick ${ }^{1}$, Joshua P. Herron ${ }^{2}$, David L. Barton ${ }^{1}$ \\ ${ }^{1}$ Physics and CASS, Utah State University,Logan, UT 84322, USA, *Email: vincent.wickwar@gmail.com \\ ${ }^{2}$ Space Dynamics Lab, Utah State University, Logan, UT 84322, USA
}

\begin{abstract}
Rayleigh-scatter lidar observations were made at the Atmospheric Lidar Observatory (ALO) at Utah State University (USU) from 1993-2004 from $45-90 \mathrm{~km}$. The lidar operated at $532 \mathrm{~nm}$ with a power-aperture-product (PAP) of $\sim 3.1$ $\mathrm{Wm}^{2}$. The sensitivity of the lidar has since been increased by a factor of 66 to $205 \mathrm{Wm}^{2}$, extending the maximum altitude into new territory, the lower thermosphere. Observations have been extended up to $115 \mathrm{~km}$, almost to the $120 \mathrm{~km}$ goal. Early temperatures from four $\sim 4$-week periods starting in June 2014 are presented and discussed. They are compared to each other, to the ALO climatology from the original lidar [1], and to temperatures from the NRLMSISe00 empirical model [2].
\end{abstract}

\section{INTRODUCTION}

The region between the maximum weather balloon altitude of $\sim 30 \mathrm{~km}$ and the minimum radar, airglow, or resonance lidar altitude of $\sim 80$ $\mathrm{km}$ can only be regularly observed from the ground by Rayleigh lidar [3]. The original ALO lidar, mentioned above, covered much of this region. A similar difficulty in making groundbased observations exists in the lower thermosphere above $\sim 100 \mathrm{~km}$. The intent of the upgraded ALO lidar is to extend Rayleigh observations up to $\sim 120 \mathrm{~km}$. The upgrade has involved a big increase in both laser power and telescope collecting area. So far the upgraded system has reached $115 \mathrm{~km}$.

One general point of making ground-based Rayleigh observations is to observe the time evolution of various aspects of the middle atmosphere. Another is to observe the coupling among regions: between the stratosphere and mesosphere and between the mesosphere and thermosphere.

A more specific and detailed statement about the science to which Rayleigh lidar contributes comes from the list of past and ongoing studies carried out using data from the original ALO Rayleigh lidar. Studies taking advantage of much of the 11year data set include a midlatitude, mesospheric temperature climatology [1], an extensive gravity wave study [4], a detailed examination of possible climate or solar cycle changes [5], a study of the midlatitude mesosphere during Sudden Stratospheric Warmings [6], and an exploration of neutral density variations [7].

In addition there are unexpected results that arise from observing as frequently as possible. These include midlatitude observations of noctilucent clouds [8,9] and their association with largeamplitude waves, and an all-night observation of a thin layer descending from the mesosphere into the stratosphere.

Furthermore, Rayleigh lidar observations are complementary to observations from satellites, such as those from SABER on TIMED [10]. Whereas the lidar can measure time evolution, the satellite can measure latitudinal and longitudinal variability. Rayleigh lidars are also complementary to resonance lidars, which have a more limited altitude range, roughly $80-100 \mathrm{~km}$, though they have better altitude and time resolution. At USU, either on campus or at the nearby Bear Lake Observatory, the ALO Rayleigh lidar observations overlap with those from a cluster of other instruments including a $\mathrm{Na}$ lidar; all-sky cameras imaging $\mathrm{OH}, \mathrm{O}\left({ }^{1} \mathrm{~S}\right)$, and $\mathrm{O}_{2}$ Atmospheric bands; a meteor wind radar; an ionosonde (for measuring $\mathrm{D}$ and $\mathrm{E}$ region ionization); and a magnetometer (for measuring E-region currents).

It is expected that the extremely sensitive ALO Rayleigh lidar will continue the types of studies described above, extending them in time and from the mesosphere into the lower thermosphere.

Section 2, on methodology, discusses the acquisition and temperature reduction of the early data from the upgraded system. Section 3, on results, shows these early temperatures and their relation to climatological and model temperatures. 
Section 4 concludes by comparing these temperatures and indicates future directions.

\section{METHODOLOGY}

Considerable data were acquired with the upgraded system during summer and fall 2014. The data were acquired during periods ranging, typically, from 4 to 10 hours. The data were averaged in time over these whole periods and 3 $\mathrm{km}$ in altitude. The analysis used the standard Chanin-Hauchecorne method involving hydrostatic equilibrium and the ideal gas law [3]. For this early work, the mesospheric composition was extended upward unaltered, giving rise to a constant backscatter coefficient and mean molecular mass. The initial value for the temperature integration at the highest altitude for each night was taken from the NRLMSISe00 (MSIS) empirical model. With this technique, the temperatures are highly accurate $10-20 \mathrm{~km}$ below the highest altitude. That altitude for each night is taken to be where the ratio of signal-to-standard deviation drops below 16. For a given night, the temperature uncertainties derived from Poisson statistics are far less than $1 \mathrm{~K}$ at $70 \mathrm{~km}$ and $\sim 12 \mathrm{~K}$ at the highest altitude. Each of the four periods had between 10 and 16 nights of observations.

\section{RESULTS}

Figure 1 shows 13 temperature profiles, in various colors, from the mid summer period 12 June-13 July extending upwards from $70 \mathrm{~km}$. The highest two nights reached $114 \mathrm{~km}$. Also shown in Figure 1 is a red curve representing the average of the observed lidar temperature profiles. At $70 \mathrm{~km}$, it is the average of all the nights in the observed period. At the highest altitudes, the top $5 \mathrm{~km}$ or so, the number of nights in the average decreases rapidly to only 1 or 2 . Because of the effects of geophysical variability and the decreasing number of profiles at the highest altitudes, this red average curve becomes noisier towards the top. Also shown in Figure 1 is a green curve between 70 and $\sim 90 \mathrm{~km}$ that represents the climatological average found with the earlier Rayleigh lidar [1]. That value is an average over a 31-night window, applied to each of the 11 years. The initial temperature value, at the highest altitude, for the data reductions for these curves was taken from the 8-year temperature climatology from the nearby $\mathrm{Na}$ lidar at Colorado State University

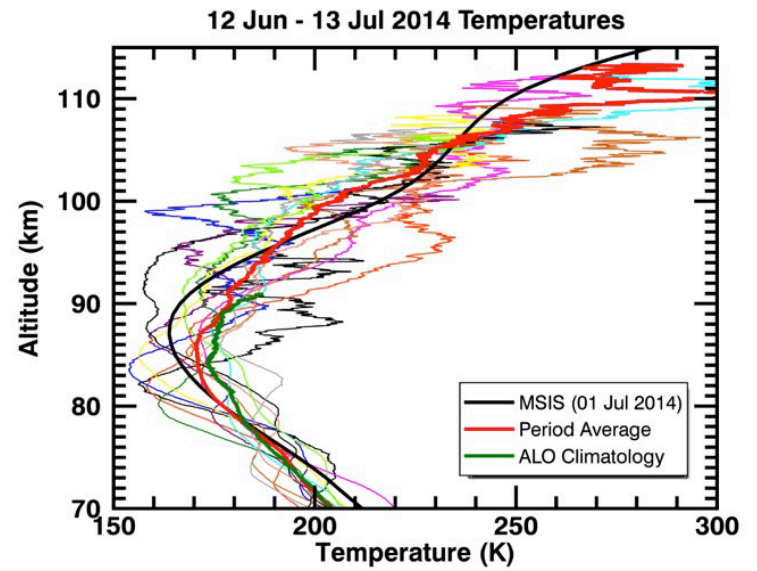

Figure 1. Nighttime temperatures in mid summer on 13 nights between 12 June and 13 July 2014, in the upper mesosphere and lower thermosphere.

(CSU) [11]. Finally, a black curve is shown between 70 and $115 \mathrm{~km}$. It is calculated from the MSIS model [2] for the center day, for 6:00 UT.

Figure 2(a) also refers to the mid-summer period, 12 June-13 July. For clarity, it reproduces only the red, green and black curves from Figure 1. Again, these three curves represent, respectively, the average temperatures for the new lidar observations, the climatological temperatures from the earlier lidar observations, and the MSIS empirical model temperatures for the center of the night, at 6:00 UT. Figures 2(b-d) show the corresponding red, green, and black curves for late summer, 14 July-17 August; early fall, 12 September-06 October; and late fall, 29 October-17 November; respectively.

\section{CONCLUSIONS}

Two contributions to the nighttime profiles stand out in Figure 1: a core of days with a $10-20 \mathrm{~K}$ band of temperatures with many small amplitude oscillations; a significant number of days with large amplitude $(\geq 20 \mathrm{~K})$ and long wavelength $(\geq 10 \mathrm{~km}$ ) waves below $\sim 100 \mathrm{~km}$.

A minimum exists in the average temperatures in Figures $2(\mathrm{a}-\mathrm{d})$ at $80-85 \mathrm{~km}$ throughout this time period. In summer the minimum at $85 \mathrm{~km}$ is the summer mesopause. It is at $\sim 170 \mathrm{~K}$ in mid summer and at $\sim 180 \mathrm{~K}$ in late summer. In fall this feature becomes a relative minimum at $\sim 80 \mathrm{~km}$. It is at $\sim 190$ in early fall and $\sim 210 \mathrm{~K}$ in late fall. 

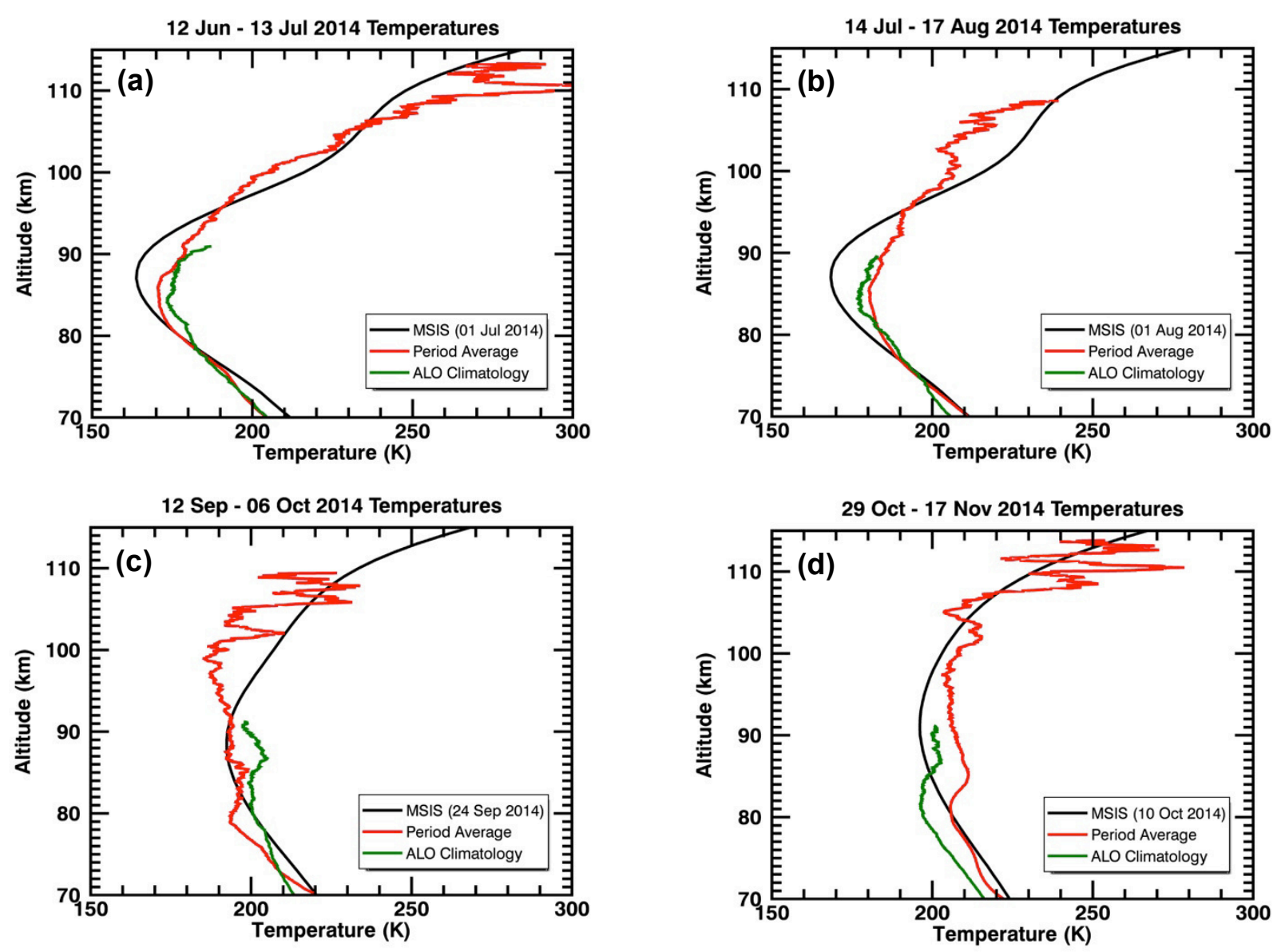

Figure 2. Average nighttime temperatures from the upper mesosphere and lower thermosphere for four periods between mid summer and late fall 2014: (a) 12 June-13 July [13 nights], (b) 14 July-17 August [16 nights], (c) 12 September-06 October [11 nights], and (d) 29 October-17 November [10 nights]. The red curves are for the current observations. The green curves are from the earlier ALO climatology. The black curves are from the MSIS model.

A second minimum appears near $100 \mathrm{~km}$ in both the early and late fall. It is the higher altitude, winter mesopause. It is at $\sim 185 \mathrm{~K}$ in early fall and $\sim 205 \mathrm{~K}$ in late fall. The transition between summer and winter behaviors occurs very rapidly in early fall.

From approximately $85-100 \mathrm{~km}$, the average new profiles follow a straight line with a slight positive slope in the two summer periods and a slight negative slope in the two fall periods. The negative slope in fall gives rise to the winter mesopause near $100 \mathrm{~km}$.

Furthermore, this $15-\mathrm{km}$ region of almost straight temperature profiles differs greatly from the MSIS profiles. The latter are curved with a minimum between 88 and $92 \mathrm{~km}$. In mid and late summer, the MSIS profiles have a mesopause $\sim 5 \mathrm{~km}$ higher and $10-15 \mathrm{~K}$ colder than the observations. In the early fall the MSIS mesopause only moves up to
$89 \mathrm{~km}$, making its temperatures $\sim 20 \mathrm{~K}$ warmer than the observed mesopause temperatures near $100 \mathrm{~km}$. In going from early to late fall, the MSIS mesopause barely moves and its temperatures increase less than the observed ones, with the result that the MSIS temperatures are now slightly colder than the observed mesopause temperatures.

Agreement of these 2014 averages and the ALO climatological temperatures from $70-90 \mathrm{~km}$ is remarkably close in summer, especially considering that the new averages are from only a few days in one year, while the climatology is from many days over 11 years. In fall the differences approach $10 \mathrm{~K}$. They are within the geophysical variability found for the climatology. This means these new results support the original ALO climatology that, with the same caveats, means they also support reasonable agreement of Rayleigh and $\mathrm{Na}$ temperatures at $90 \mathrm{~km}$ during these four periods. At that altitude, the new temperatures are 
good because the downward integration started $\sim 20 \mathrm{~km}$ higher. The initial values near $90 \mathrm{~km}$ for the ALO climatology, in contrast, are based on the CSU Na climatology [11].

In the future, assuming that funding is available, the top altitude will be raised and regular observations will continue. The bottom altitude will be lowered with continuing system improvements, including more detector channels. Extensive comparisons will also be carried out with observations from the other instruments in the USU mesospheric cluster.

While this lidar opens the mesosphere and lower thermosphere to ground-based observations at one mid-latitude location, it suggests the future importance of developing more affordable and simpler Rayleigh systems with comparable sensitivity that can be acquired and operated by small research groups as part of a global network at many locations around the world.

\section{ACKNOWLEDGMENTS}

We gratefully acknowledge support for this work from a Space Dynamics Lab IR\&D grant, Utah NASA Space Grant Consortium, Howard L. Blood and Gene Adams Graduate Scholarships, USU, USU College of Science, USU Physics Department, personal contributions, and the work of many students: Thomas Amely, Marcus Bingham, Ryan Martineau, Luis Navarro, and Lance Petersen. Many of the observations were carried out by a dedicated group of students: Jordan Burns, Preston Hooser, David Moser, Rebecca Petrick, Warren Schweigert, Patrick Sharp, Joe Slansky, and Bryant Ward. The observatory, telescope, and laser laboratory were built with funds from NSF, AFOSR, and USU.

\section{REFERENCES}

[1] Herron, J.P., 2007: Rayleigh-Scatter Lidar Observations at USU's Atmospheric Lidar Observatory (Logan, UT) - Temperature Climatology, Temperature Comparisons with MSIS, and Noctilucent Clouds, PhD Dissertation, 156 pp, Utah State University, Logan, UT.

[2] Picone, J. M., A. E. Hedin, D. P. Drob, and A. C. Aikin, 2002: NRLMSISE-00 empirical model of the atmosphere: Statistical comparisons and scientific issues, J. Geophys. Res., 107(A12), 1468-1483, doi:10.1029/2002JA009430.

[3] Hauchecorne, A., and M. L. Chanin, 1980: Density and temperature profiles obtained by lidar between 35 and $70 \mathrm{~km}$, Geophys. Res. Lett. 7, 565-568.

[4] Kafle, D. N., 2009: Rayleigh-lidar observations of mesospheric gravity wave activity above Logan, Utah, PhD Dissertation, 209 pp, Utah State University, Logan, UT.

[5] Wynn, T. A., 2010: Statistical analysis of the USU lidar data set with reference to mesospheric solar response and cooling rate calculation, with analysis of statistical issues affecting the regression coefficients, $\mathrm{PhD}$ Dissertation, $232 \mathrm{pp}$, Utah State University, Logan, UT.

[6] Sox, L, V. B. Wickwar, C. Fish, J. P. Herron, 2015: Temperature deviations in the midlatitude mesosphere during stratospheric warmings as measured with Rayleigh-scatter lidar, ILRC27.

[7] Barton, D. L., V. B. Wickwar, J. P. Herron, L. Sox, L. A. Navarro, 2015: Variations in Mesospheric neutral densities from Rayleigh lidar observations at Utah State University, ILRC27.

[8] Wickwar, V. B., M. J. Taylor, J. P. Herron, B.A. Martineau, 2002: Visual and lidar observations of noctilucent clouds above Logan, Utah, at $41.7^{\circ} \mathrm{N}, J$. Geophys. Res., 107(D7), 4054-4059, 10.1029/2001JD001180.

[9] Herron, J. P., V. B. Wickwar, P. J. Espy, and J. W. Meriwether, 2007: Observation of a noctilucent cloud above Logan, Utah $\left(41.7^{\circ} \mathrm{N}\right.$, $\left.111.8^{\circ} \mathrm{W}\right)$ in 1995, J. Geophys. Res., 112 (D19203), 10.1029/2006JD007158.

[10] Mertens, C. J., et al., 2004: SABER observations of mesospheric temperatures and comparisons with falling sphere measurements taken during the 2002 summer MaCWAVE campaign, Geophys. Res. Lett., 31 (L03105), doi:10.1029/2003GL018605.

[11] She, C. Y., et al., 2000: Eight-year climatology of nocturnal temperature and sodium density in the mesopause region (80 to $105 \mathrm{~km}$ ) over Fort Collins, CO $\left(41^{\circ} \mathrm{N}, 105^{\circ} \mathrm{W}\right)$, Geophys. Res. Lett., 27(20), 3289-3292. 